\title{
Construction of Tianjin Agricultural Science and Technology Achievement Transformation Model
}

\author{
Xia Yang \\ The science and Technology Department \\ Tianjin Agricultural University \\ Tianjin, 300384, China \\ tjqingqingcao@163.com
}

\author{
Qiaoli Zhang \\ The science and Technology Department \\ Tianjin Agricultural University \\ Xiqing District, Tianjin, 300384, China \\ qlizhang@163.com
}

\begin{abstract}
Accelerating the transformation of scientific and technological achievements into practical productivity has always been an important issue to be solved in economic development. It is also an important task for scientific and technological work to face the main battlefield of economic construction. The transformation of scientific and technological achievements is an important topic discussed by scientific and technical personnel and scientific and technological managers. This article summarized the measures and transformation models adopted in the transformation of achievements in Tianjin in recent years, such as Building government guidance mechanism relying on transformation and promotion of agricultural science and technology achievements; Loan interest subsidy policy supports the transformation of corporate investment results; Leveraging the coordinated development of Beijing, Tianjin and Hebei and strengthening scientific and technological cooperation; Accelerate Platform Construction; Starting the construction of a modern industrial technology system; Strengthen fund management and improve incentive mechanisms to ensure safe and efficient results transformation and so on. These models provided references for the transformation of achievements in different regions.
\end{abstract}

Keywords-Agriculture; Scientific and technological achievements; Transformation model

\section{INTRODUCTION}

At present, the transformation of agricultural scientific and technological achievements was achieved through the promotion of agricultural technology. It was a relatively important and effective transformation route that we have adopted all along [1-2]. However, the fact that the conversion rate of scientific and technological achievements was not high over the past few years proves that it was still not enough to rely solely on technology promotion. There were still many ways to explore the transformation of agricultural scientific and technological achievements, and there were many more important and more effective forms to further promote the transformation of agricultural scientific and technological achievements [3].

All along, many government departments, research institutes, colleges and universities were constantly exploring the transformation of scientific and technological achievements. Industry-university-research institute cooperation, government-enterprise cooperation, local school cooperation, etc. Practice has proved that the transformation of

The research was sponsored by Project of Tianjin rural work committee (Project No: 201105020) and Scientific research and development fund project of Tianjin Agricultural University (Project No: 2011S02). scientific and technological achievements was not a single model to play a role, often bringing together many factors such as policies, funds, and the environment[4]. On August 29, 2015, the 16th Session of the Twelfth National People's Congress adopted the new "Promotion of the Transformation of Scientific and Technological Achievements" and implemented it on October 1, 2015. In the recent 20 years, the Law on the Promotion of Transformation of Scientific and Technological Achievements was revised, highlighting the importance that the country will place next on the transformation of scientific and technological achievements.

The Tianjin Municipal Committee and the Municipal Government also attached great importance to the transformation of scientific and technological achievements. On July 26, 2017, the 37th meeting of the Standing Committee of the 16th Tianjin People's Congress adopted the Regulations of the Tianjin Municipality on the Promotion of the Transformation of Scientific and Technological Achievements. It has now officially been published. The transformation of agricultural scientific and technological achievements has its own particularities. Sometimes the implementing subject was the peasant, so there was a certain degree of difficulty in transforming it. The Tianjin Rural Work Committee, as the competent department of agriculture, has been working hard to explore the transformation of scientific and technological achievements. The contribution rate of agricultural science and technology progress has reached $60.4 \%$, which has ensured the development of Tianjin's coastal urban modern agriculture and the construction of new rural areas in the forefront of the country.

\section{DiFFERENT TRANSFORMATION MODES}

A. Building government guidance mechanism relying on transformation and promotion of agricultural science and technology achievements

Science and technology was the fundamental way to accelerate agricultural development and increase farmers' income. The lag in agricultural scientific research system will affect the advancement of agricultural science and technology. The government's guiding mechanism has become more and more important. The government continues to strengthen and improve the project guidance mechanism, continuously increases the support of the project, and explores the reasonable procedures, evaluation methods, and organizational 
methods of the project review. And work hard on the project guidelines to achieve comprehensive research, focus on mastery, and go to the production line to understand the problems that farmers and enterprises need to solve in the actual production process, break through the bottleneck and solve difficult problems, and target projects to support the ripening of scientific and technological achievements and timely applied to the actual production, and continuously promote the progress of agricultural science and technology. At present, some government departments such as the Tianjin Animal Husbandry and Veterinary Bureau have already tried the tendering system for the project. This requires the government departments to be very clear about the technical needs or problems to be solved, and the evaluation indicators are very clear and quantifiable. In the same way, the bidding unit will also require more advanced technologies and supporting technologies, talents and capabilities to solve related problems.

From 1989, Tianjin began implementing agricultural technology extension projects. In accordance with the development goals set by the annual rural work conference, the plan arranges a small amount of funds, concentrates the scientific and technological forces, and promotes the adoption of agricultural science and technology to solve the key technical issues that were prominent at the time. With the promulgation and implementation of the Agricultural Technology Promotion Law in 1993 and the strategy for the promotion of agriculture through science and education, the municipal government continuously increased its support for agricultural science and technology. In 1999, the special fund reached 2.05 million Yuan. With the development of scientific and technological cooperation, the funds for the transformation and promotion of scientific and technological achievements in 2001 reached 5.5 million Yuan. By 2004, the funds had achieved a breakthrough and reached 20 million Yuan per year. A series of related policies including funding arrangements, project management, and expense management were successively issued, which standardized the project's guidelines for research and publication, organization of reporting demonstration, confirmation of support projects, signing of the contract and implemented management, improved project management rules, and launched a series of project management personnel training to ensure the smooth implementation of the project and play a crucial role in the process of agriculture through science and education. By 2007, the funds for the transformation and promotion of agricultural scientific and technological achievements had doubled from 2004[5-8]. This policy was mainly used to support key technologies that can promote the sustainable development of agriculture, increase farmers' income, agricultural product safety, industrial upgrading, transformation and promotion of new technologies, new varieties of agriculture, key technologies for agriculture and rural public welfare, and gave priority to support industry upgrading has important significance in the demonstration and promotion of integrated technologies.

On December 15, 2016, the Standing Committee of the 16th Tianjin People's Congress revised and adopted the "Measures for the Implementation of the Agricultural
Technology Extension Law of the People's Republic of China in Tianjin" and implemented it on March 1, 2017, which clearly indicated The Municipal People's Government shall establish a special fund for the transformation and promotion of agricultural scientific and technological achievements, support the transformation and demonstration and popularization of agricultural scientific and technological achievements, the introduction of varieties of technical equipment, and the scientific and technological cooperation with some state-level research institutes. There was a legal basis for the transformation and promotion of scientific and technological achievements, which effectively guarantees the investment in the transformation and promotion of scientific and technological achievements.

\section{B. Loan interest subsidy policy supports the transformation of corporate investment results}

In order to encourage enterprises to make efforts in the transformation of scientific and technological achievements and transform the achievements into reality, Tianjin has tried to subsidize the transformation of the main body by means of loan interest subsidy, establish a seed industry base, develop the dominant source of agriculture in this city, and enhance the international competition of Tianjin seed industry. In 2008, the Tianjin Rural Work Committee, the Tianjin Science and Technology Commission, and the Tianjin Finance Bureau launched a seed industry base construction project, printed and issued the "Opinions on the Construction of the Tianjin Agricultural Seed Industry Base,” and together with the Tianjin Finance Bureau, formulated the "Tianjin City Measures for the Administration of Special Funds for Loans Subsidized by Agricultural Seed Production Bases [9,10]. In 2015, the Measures for Loan Subsidy for Agricultural Seed Bases in Tianjin were reprinted[11]. At present, the breeding bases for superior varieties of vegetables, pigs, cows, freshwater fish, etc. have been launched, infrastructure construction has been improved, the scale of breeding bases has been expanded, breeding capacity has been improved, and a seed quality inspection system, parental breeding gene bank, and demonstration of vegetable varieties have been established, transformation platform and breeder breeding system, sperm supply station and artificial insemination station. The next step will be to establish breeding bases for improved varieties of rice, rare seafood, flowers, fruit, edible fungi and other industries. After completion, it was expected that each breeding base will have a complete seed breeding base and modern seeds production, testing, processing, and storage capabilities. Each base will have an annual sales income of more than 30 million Yuan, and new social and economic benefits will reach 10 billion Yuan. This will bring great opportunities for the rapid development of the agricultural seed industry in Tianjin.

\section{Leveraging the coordinated development of Beijing, Tianjin and Hebei and strengthening scientific and technological cooperation}

Introduce the use of external intelligence to serve the advancement of science and technology in Tianjin. Tianjin has successively signed scientific and technological cooperation agreements with several well-known national agricultural research institutes and agricultural universities, including the 
Chinese Academy of Agricultural Sciences, the China Agricultural University, the Chinese Academy of Forestry, the Chinese Academy of Fishery Sciences, and China's agricultural mechanization research, the Ocean University of China, and Tokyo University of Japan, with their support for well-known experts in cooperative universities, have come to Tianjin for cooperation and will use their advanced technological achievements to take root in Tianjin to serve the construction of Tianjin's new countryside. In the cooperation and exchange activities in December 2006, it was determined that a total of five scientific experiments and achievement transformation bases will be established in Tianjin. The construction of five bases has established a platform for deep cooperation between experts in Tianjin and other places, changed the status quo of cooperation through only a single project in the past, and established the sub-topics and the right to use funds, and the research team established the results according to the actual situation. The content of the transformation and the problems to be solved give the research group more space for more independence.

In order to implement the "Beijing-Tianjin-Hebei Coordinated Development” national strategy and Tianjin Municipal Government's "Take advantage of the capital resources to promote the development of Tianjin” action plan, in March 2017, the Agriculture Commission of the People's Republic of China held a symposium on collaborative development of scientific research with the Chinese Academy of Agricultural Sciences and the Chinese Academy of Forestry, carry out cooperation and docking work. With regard to the new progress, new ideas, and new measures in Tianjin's agricultural and rural work, the next step was cooperation intention. The two scientific research institutes were arranging for the relevant departments to quickly establish expert groups to conduct in-depth docking and planning with the city.

\section{Accelerate Platform Construction}

In recent years, Tianjin City was investing heavily in the construction of the Binhai New Area Agricultural Science and Technology Park. The Tianjin Binhai Eco-agricultural Science and Technology Park, Binhai Chadian Grape Science and Technology Park, Binhai International Flower Science and Technology Park, Binhai Salt-tolerant Plant Science and Technology Park, and Binhai Yangjiabo Aquatic Science and Technology Park, Binhai Aquarium Science and Technology Park, Binhai Aolv Agriculture Science and Technology Park, Tianjin Mengde Cow Technology Park, were currently under construction etc.[12].At present, they were actively exploring and improving the park's operating mechanism, improving the park's gathering and radiation functions, hatching and nurturing functions, demonstrations, and driving functions, building a sound environment for the industrialization of science and technology, developing science and technology-oriented enterprises. The completed park will also build a broader platform for scientific research and the transformation of achievements, and will attract more leading enterprises to invest in Tianjin and incubate more excellent scientific and technological achievements.

In addition, in the two years of 2015 and 2016, Tianjin City has identified 70 units as Tianjin Science and Education and Agricultural Integrated Innovation Demonstration Base, focusing on seed industry, biological agriculture and so on. The National Agricultural Science and Technology Innovation and Integration Demonstration Base identified by the Ministry of Agriculture as the Tianjin Academy of Agricultural Sciences is regarded as the demonstration base of integrated innovation of agriculture, science and education in Tianjin[13]. All base construction units were required to actively undertake the application of demonstration agricultural new varieties and new technologies, establish a long-term mechanism in which agricultural science and technology were closely integrated with production, gather science and education resources, increase the content of agricultural science and technology, drive farmers to increase income, and promote the development of modern urban agriculture in our city. It also requested that the transformation and promotion projects of agricultural scientific and technological achievements being implemented should focus on demonstrating at these bases as much as possible. Give full play to the science and technology innovation and demonstration leading role of the base.

\section{E. Starting the construction of a modern industrial technology system}

In 2013, the author proposed a proposal for the development of a modern agricultural industrial technology system in Tianjin and a construction plan [14]. In 2017, Tianjin City learned from the construction and requirements of a national industrial technology system, based on aquatic products, vegetables, pigs, and dairy cows. Four industries started the construction of an innovative team of industrial technology systems [15-19]. Although the work of Tianjin's agricultural industrial technology system started relatively late, the construction work was carried out on the principle of high demand and high standards, with a total investment of 100 million Yuan. In the four systems, 4 well-known experts from the Tianjin Academy of Agricultural Sciences and Tianjin Agricultural College were employed as the industry's chief experts, 64 job experts were identified, and 49 comprehensive experimental stations were established. The establishment of the innovation team considers the research and development of technology and the transformation and promotion of results from the work level. It considers breeding, supporting technologies, pre-production, post-production, post-production and industrial economy from an industrial perspective. And established a working mechanism for QQ, WeChat contact and reporting in a timely manner, and set up an expert team to solve production problems in an emergency. It will be more systematic, more complete, and more clear-cut in its objectives to enhance industrial development. A few days ago, the appointment of the chief expert of the industrial systems of rice and forestry industries was completed. Two innovation teams are already working.

With the development and promotion of the system construction work, a batch of new varieties will be cultivated, a batch of new technologies will be transformed, some production problems will be solved, new research points will be discovered, a batch of new patents will be obtained, and a batch of farmers will be trained. The establishment of a comprehensive experimental station has provided a platform for the display of new varieties and new technologies, provided a model reference for farmers, played an inestimable 
role in demonstration, and made it easier and more proactive for farmers to accept new things and accelerated the transformation of scientific and technological achievements.

\section{F. Strengthen fund management and improve incentive mechanisms to ensure safe and efficient results transformation}

Project funding was a necessary condition for ensuring the transformation of results, and ensuring the safe and effective use of funds was the prerequisite for the transformation of results. We must further strengthen the management of capital projects, improve the efficiency and effectiveness of the use of funds, integrate strengths, integrate resources, and vigorously support the implementation of agricultural scientific and technological achievements transformation and promotion projects; timely coordinate the work of the project undertaking units; and actively create a guarantee for the smooth implementation of projects surroundings.

The new "Promotion of the Transformation of Scientific and Technological Achievements" and the Tianjin Regulations on the Promotion of the Transformation of Scientific and Technological Achievements have clearly defined incentive policies for personnel and encouraged the scientific and technical personnel to leave their posts to start a business or part-time job and start a business. They also have technicians who have made outstanding contributions in the process of transforming achievements. Proper care was given in the evaluation of professional titles, and clear provisions were made for the distribution of benefits from the transformation of scientific and technological achievements, which ensures the scientific and technical personnel's reasonable return in the process of transforming achievements and improves the enthusiasm of scientific and technological personnel to participate in the transformation of results and active transformation. The transformation of scientific and technological achievements has been put on an unprecedented new height.

\section{CONCLUSION}

The transformation of scientific and technological achievements has no successful experience that can be copied. Different regions will face different problems and have unique local conditions. Therefore, the transformation of the achievements of any locality or department can only learn from some successful models, summarize the transformation pathways that were suitable for them, and continue to explore on the road to transformation of achievements. We hope that Tianjin's achievements transformation model will give us some experience.

\section{REFERENCES}

[1] A Precedent for Intermarriage between China and Foreign Countries. [2015-3-22]. http://blog.sina.com.cn/s/blog_90cdccac0102vpbo.html.

[2] Zhou Bo, Wang Gang, Wang Lei. Empirical research on the transformation model of agricultural high-tech achievements in Heilongjiang province. Management of Agricultural Science and Technology, vol.2(28), pp.79-82,2009, (In Chinese).

[3] Zhang Hong, Huang Yuan, Chen Jinyuan. Several Strategies for the Transformation of University Scientific and Technological Achievements. Science and Technology Management Research, vol. 36(17),pp.102-105,2016,(In Chinese).
[4] Duan Xianjie. Research on the Transformation Model of Scientific and Technological Achievements in Taiyuan City. Taiyuan Science and Technology, vol.1,pp.21-23,2004,(In Chinese).

[5] Tianjin Rural Work Committee, Tianjin Finance Bureau. Circular on Capital Arrangements for Transformation and Promotion of Agricultural Science and Technology Achievements, Jin Agriculture Committee [2004] No. 59, Jin Financial Agricultural Union [2004] No. 42, 2004. (In Chinese).

[6] Tianjin Rural Work Committee, Tianjin Finance Bureau. Notice on Printing and Distributing the "Trial Measures for the Management of Tianjin Agricultural Scientific and Technological Achievements Transformation and Promotion Projects". Jin Agriculture Committee [2005] No.54, Jin Financial Agricultural Union[2005] No. 38, 2005. (In Chinese).

[7] Tianjin Finance Bureau. Notice on Printing and Distributing the "Tianjin Municipal Agricultural Science and Technology Achievement Transformation and Promotion Special Fund Management Measures". Jin Financial Agricultural Union [2007] No. 51, 2007. (In Chinese).

[8] Yang Xia, Zhang Qiaoli. Tianjin Agricultural Science and Technology Achievement Transformation and Promotion Project Management. Industry and Technology Forum,vol.09 (10),pp.59-62, 2010, (In Chinese).

[9] Huang Jiangao, Geng Junyao. Tianjin has accelerated the construction of ten major seed bases in an all-round way. Beijing Agriculture, vol.2, p.52, 2010, (In Chinese).

[10] Tianjin Science and Technology Commission, Tianjin Rural Work Committee, Tianjin Finance Bureau. Notice on Printing and Distributing Opinions on the Construction of Tianjin Agricultural Seed Industry Base. Jin Agriculture Committee[2008]4, 2008. (In Chinese).

[11] Tianjin Rural Work Committee, Tianjin Finance Bureau. Notice on Printing and Distributing the Loan Subsidy Interest of Agricultural Seed Plant Base in Tianjin, China. Jin Agriculture Committee Finance [2015] 18, Jin Financial Agricultural Union[2015] No. 65, 2015. (In Chinese).

[12] General Office of the Tianjin Municipal People's Government. Notice of the Forwarding of the Proposals of the Coastal Committee of the Agriculture Committee of the Municipal Agriculture Committee of the City on Promoting the Construction of the Coastal Agricultural Science and Technology Park. Jin government[2008]No. 58, 2008. (In Chinese).

[13] Notice of Tianjin rural work committee on the identification of the first batch of Tianjin science and education integrated innovation demonstration base. Jin Agriculture Committee[2015] No. 30, 2015. (In Chinese).

[14] Zhang Qiaoli, Yang Xia. Study on the Construction of Tianjin Modern Agricultural Industrial Technology System. Science and Technology Management Research, vol.18,pp.163-166, 2013, (In Chinese).

[15] The approval and reply of Tianjin rural working committee on the implementation plan of Tianjin vegetable industry technical system innovation team construction. The accounting department of the rural work committee of Tianjin letter[2016] No.44, 2016. (In Chinese).

[16] The approval and reply of Tianjin rural working committee on the implementation plan of Tianjin pig industry technology system innovation team construction. The accounting department of the rural work committee of Tianjin letter[2016] No.45, 2016. (In Chinese).

[17] The approval and reply of Tianjin rural working committee on the implementation plan of Tianjin dairy industry a technology system innovation team construction. The accounting department of the rural work committee of Tianjin letter[2016] No.46, 2016. (In Chinese).

[18] The approval and reply of Tianjin rural working committee on the implementation plan of Tianjin aquaculture technology system innovation team construction. The accounting department of the rural work committee of Tianjin letter[2016] No.43, 2016. (In Chinese).

[19] Circular of Tianjin rural work committee and Tianjin municipal finance bureau on the issuance of "measures for the management of special funds for the construction of modern agricultural industrial technology system innovation team in Tianjin". Jin Agriculture Committee Finance [2016] No.105, 2016. (In Chinese). 